1 Universidade Federal do Rio Grande do Sul (UFRGS), Programa de Pós-Graduação em Psicologia Social e Institucional - Porto Alegre (RS), Brasil. fernandamacedo.fsm@ gmail.com

2 Universidade Federal do Rio Grande do Sul (UFRGS), Programa de Pós-Graduação em Antropologia Social e Programa de PósGraduação em Psicologia Social e Institucional Porto Alegre (RS), Brasil. machadops@gmail.com

\section{Economia moral e modelos de atenção no cuidado com gestantes que usam crack}

\author{
Moral economy and care models in the care of pregnant women who \\ use crack
}

Fernanda dos Santos de Macedo', Paula Sandrine Machado ${ }^{2}$

RESUMO Este artigo resultou de uma pesquisa etnográfica sobre a atenção a gestantes que usam crack, tomando como fio analítico-conceitual a noção de economia moral. A etnografia foi realizada em dois serviços públicos de saúde (Hospital e Consultório na Rua). Visou-se analisar uma das dimensões que conformam a economia moral, os elementos referentes aos modelos de atenção e como esses são enfatizados e atualizados nos serviços. Percebeu-se que elementos dos modelos, ao serem acionados nos serviços, influenciam as práticas de cuidado, refletindo na percepção e posicionamento das equipes diante da relação com as gestantes, bem como do tratamento e direitos delas e de seus bebês.

PALAVRAS-CHAVE Gestantes; Cocaína crack; Atenção à saúde.

\begin{abstract}
This article results from an ethnographic research about the care of pregnant women who use crack, using as the central conceptual operator the notion of moral economy. Ethnography was developed in two public health services. The goal was to analyzed one of the dimensions that conform to moral economy, the elements relating to models of care, and how those are emphasized and updated in services. It was noted that when elements of the models are triggered in service, they may influence care practices, reflecting in the health staff perception and positioning before the relationship with pregnant women, as well as the treatment and their rights and the rights of their babies.
\end{abstract}

KEYWORDS Pregnant women; Crack cocaine; Health care (Public health). 


\section{Introdução}

Neste artigo, apresentam-se alguns resultados que integram uma pesquisa mais ampla, cujo objetivo foi analisar como opera a economia moral nas cenas de cuidado em relação à atenção a gestantes que fazem uso de crack em dois serviços de saúde no estado do Rio Grande do Sul. A economia moral, segundo Didier Fassin (2014), diz respeito às dimensões acionadas nos processos de valoração e hierarquização da noção de cidadania que conformam os tratamentos direcionados às vidas. Sendo assim, tal análise permitiu observar as articulações entre moralidades no campo das drogas e de gênero que conformam as práticas direcionadas às gestantes que usam crack, como as propostas terapêuticas, as escolhas reprodutivas e a avaliação e investimento na relação da mulher com seus/suas filhos/as.

Compreende-se que, nos contextos de saúde pesquisados, a economia moral é conformada pela inter-relação de dimensões de reflexão, sendo elas: elementos atinentes aos modelos de atenção enfatizados nos serviços - que correspondem ao contexto institucional e a pressupostos ético-políticos de cuidado; grupo social - no que diz respeito aos valores e princípios compartilhados como certos ou errados na equipe e/ou na sociedade e, igualmente, pelos aspectos individuais dos/as profissionais - experiências pessoais e profissionais. Neste momento, analisar-se-á a dimensão referente aos modelos de atenção - apresentados nesse contexto como modelo com ênfase hospitalar e modelo com ênfase psicossocial, posto que se tem como hipótese que o modo como são operacionalizados tais modelos também informa a economia moral.

O debate acerca dos modelos de atenção à saúde no Brasil reporta à transformação no sistema de saúde proposto pelo Movimento de Reforma Sanitária (MRS), associando-se ao processo de elaboração do Sistema Único de Saúde (SUS). Sendo assim, a bibliografia sobre essa questão é ampla, como pode ser visto em Carmen Teixeira e Jorge Solla (2006) e Jairnilson Paim (2008). Neste artigo, o foco é considerar que as políticas de saúde no Brasil podem ser expressas por meio de modelos de atenção, que incitam práticas de cuidado. Como o objeto da pesquisa de que trata este artigo foi analisar a atenção a gestantes que usam crack, busca-se situar as práticas profissionais direcionadas a elas em lógicas de saúde mais amplas, isto é, analisar de que modo os serviços acionam em maior ou menor medida elementos de um determinado modelo e, ainda, por vezes, como transitam entre eles.

Com a reforma psiquiátrica, iniciou-se a discussão nas políticas públicas sobre abordar uso e abuso de álcool e outras drogas de modo a oferecer atenção integral e integrada em diferentes áreas e levando-se em conta a complexidade do cuidado (CFP, 2013). $O$ redirecionamento da assistência em saúde mental no País privilegia o tratamento em serviços abertos, não hospitalares e de base comunitária. Desse modo, a adoção do paradigma da Redução de Danos (RD) nas políticas de saúde e socioassistenciais impulsiona o desenvolvimento de práticas de cuidado que partem da defesa dos direitos humanos das pessoas que fazem uso de drogas (BRASIL, 2003B).

Em contrapartida, programas baseados na internação em hospitais ou comunidades terapêuticas demonstram que, no Brasil, coexistem práticas de atenção à saúde respaldadas em uma visão hospitalocêntrica e estratégias baseadas na perspectiva psicossocial. Sendo assim, tais políticas e medidas implementadas contribuem para acirrar a tensão política, econômica e social que engloba a atenção a pessoas que fazem uso de crack no País. Todavia, no âmbito das práticas cotidianas em saúde, as políticas e medidas vigentes são acionadas pelos/as profissionais de saúde conforme as percepções diante do caso, por isso merecem uma reflexão a partir de suas nuances e controvérsias. 
A discussão elaborada por Priscila Barroso (2013) sustentará as análises do presente artigo no que se refere aos modelos de atenção a pessoas que fazem uso de drogas. Em sua pesquisa sobre a intervenção e tratamento direcionados a usuários de drogas, a autora destaca os seguintes modelos: 1) modelo de atenção com ênfase hospitalar; e 2) modelo de atenção com ênfase psicossocial. Segundo ela, não se trata de pensá-los enquanto estáticos e coesos, pois são tensionados pela sociedade e pelos atores neles inseridos (profissionais, usuárias/os) e, portanto, atualizam-se na prática. $\mathrm{O}$ que principalmente interessa na pesquisa de Barroso (2013) é analisar de que forma os elementos das propostas (desintoxicação, reinserção social, prescrição de medicamentos e abordagem multidisciplinar) são acionados pelos/as profissionais para compor cada modelo da rede de atenção a usuários/as de drogas.

Emerson Merhy (1998) também se dedica a refletir acerca de modelos de atenção à saúde como modos de produzir saúde. Argumenta que a produção do cuidado se centra na micropolítica do trabalho vivo em ato. Portanto, a partir da análise dos processos cotidianos do trabalho, evidencia-se a produção de vozes, escutas, silêncios expressos em formas definidas por/em modelos de atenção. Revelar as lógicas que operam nos processos de trabalho em saúde - na dimensão relacional - contribui na percepção sobre os significados ético-políticos envolvidos nesse processo.

Para Merhy (2004), além da combinação de tecnologias que conforma modelos de atenção, há nesses uma dimensão cultural, ética e política. Assim, segundo o autor, os modos tecnológicos de atuar em saúde são definidos e organizados a partir de forças sociais. Visto que tais forças direcionam interesses naquilo que se está produzindo no setor saúde, é evidente que as conformações tecnológicas são implicadas social e politicamente. Logo, tal discussão enuncia sobre modelos de atenção em saúde que apontam para pressupostos ético-políticos acionados nas decisões e ações cotidianas dos profissionais. Isto é, no que tange à atenção a gestantes que usam crack, a produção do cuidado e as decisões que são tomadas em relação a elas inscrevem-se nas lógicas de saúde e propostas terapêuticas produzidas nesses e por esses modelos.

A pesquisa a qual se refere este artigo foi motivada pelo crescente debate acerca da dita epidemia de crack no País, bem como pelas reverberações que a inserção do feminino causou nesses debates. Isto é, afastou-se a díade crack/criminalidade, que fora recorrente nos discursos midiáticos analisados em estudo anterior, no qual o perfil era predominantemente de homens jovens (ROSO ET AL., 2013), e passou-se a vincular o uso de crack a um problema de saúde pública, quando esse uso era feito por mulheres, especialmente quando essas estavam grávidas (MACEDO; ROSO; LARA, 2015). A Política Nacional sobre Drogas vigente em 2005 evidenciava a ausência de propostas que se ocupassem da atenção a mulheres no campo das drogas.

Tendo em vista os significados atribuídos ao uso de crack por mulheres e as políticas públicas direcionadas a elas, considera-se importante atentar para como as equipes de saúde, que atuam como porta-vozes das políticas públicas, pensam e desenvolvem práticas de cuidado, sobretudo quando se concebe a saúde pública enquanto produção social. Didier Fassin (2004) rejeita uma noção de saúde pública preexistente e a considera enquanto reconstrução diária e local de práticas. Assim, auxilia a pensar as configurações plurais de saúde pública que se alternam em cada contexto social.

Fassin (2013) empenha-se em analisar as situações e práticas cotidianas, observando-as no contexo social e político mais amplo que as tornou possíveis. Sendo assim, ao abordar a questão da atenção à saúde de gestantes que usam crack, entende-se ser crucial compreender de que modo as características dos 
modelos de atenção conformam práticas profissionais e, ao mesmo tempo, como esses atores tensionam tais modelos. Portanto, expor-se-ão situações em que se percebe que as características atinentes aos modelos conformaram modos de prestar o cuidado e influenciaram na construção das propostas terapêuticas. A análise foi conduzida pela observação de dois aspectos que se evidenciaram na produção desse cuidado: as concepções sobre drogas e o vínculo.

\section{Método}

Este artigo resulta de uma pesquisa etnográfica realizada em dois serviços de saúde do estado do Rio Grande do Sul: uma Unidade de Internação Psiquiátrica em um hospital e um Consultório na Rua. Ambos integram a rede municipal de saúde e oferecem integralmente atendimento pelo SUS. São compostos por equipes multidisciplinares, e, entre o público para o qual são referência, estão as gestantes que usam drogas.

A etnografia configurou-se por um trabalho de campo ${ }^{\mathbf{1}}$ de aproximadamente três meses, realizado pela primeira autora deste artigo, que acompanhou o cotidiano dos serviços, principalmente, as atividades e atendimentos referentes às gestantes que usam crack. O corpus analítico do estudo configurou-se a partir de observações-participantes, relatos em diário de campo, análise de prontuários das gestantes e de entrevistas semiestruturadas com seis profissionais, três de cada serviço. Os/as profissionais entrevistados/as foram escolhidos em função: 1) da percepção sobre a relação desses/as profissionais com o cuidado às gestantes que usam crack (engajamento no caso, frequência dos atendimentos, ser referência para uma usuária/paciente); 2) do cargo exercido, ou seja, aqueles que possuem tarefas de coordenação das equipes, longa trajetória com esse trabalho; e, ainda, 3) da relação da pesquisadora com cada profissional, o que influenciou no convite e aceite.

Essa pesquisa foi avaliada e aprovada pelo Comitê de Ética em Pesquisa (CEP) do Instituto de Psicologia da Universidade Federal do Rio Grande do Sul, sob o parecer $\mathrm{n}^{0}$ 1.096.658, bem como pelos CEPs dos serviços onde foi realizado o trabalho de campo de acordo com a legislação e normativas vigentes.

\section{Resultados e discussão}

A pesquisa em diferentes serviços possibilitou a análise de como são articuladas na rede de saúde as práticas de atenção a gestantes que usam crack, em momentos, ou níveis, distintos: prevenção, pré-natal, internação, perinatal. Considera-se que os serviços estudados acionam diferentes perspectivas ético-políticas sobre cuidado e, ao contrastá-los, ampliou-se a percepção sobre a efetivação desse cuidado e de que forma as/os profissionais agenciam diretrizes institucionais, pressupostos científicos e teóricos, 'evidências' e princípios morais. Identificaram-se dois modelos que operam o cuidado de formas diferentes e que, por vezes, conectam-se em rede. Como o intuito neste escrito é apresentar os aspectos que se destacam em cada serviço, sem necessariamente compará-los, passa-se a descrevê-los e analisá-los separadamente.

\section{O Consultório na Rua}

O Consultório na Rua (CR) é compreendido neste estudo como inscrito no modelo de atenção com ênfase psicossocial, posto que integra o componente 'atenção básica' da Rede de Atenção Psicossocial (BRASIL, 2011), e, também, por ter como diretriz desenvolver o cuidado no território, integrado ao contexto dos sujeitos. Dessa forma, o CR presta atendimento inicial, encaminhando as questões que ultrapassam sua capacidade resolutiva para outro nível de atenção do sistema.
1 O trabalho de campo foi realizado com objetivo de produção da dissertação de Mestrado: 'A Economia Moral na atenção a gestantes que usam crack: uma análise das práticas cotidianas de cuidado', de autoria da primeira autora sob orientação da segunda autora. 
2 Serão utilizados os termos 'usuária' ou 'dependente química', fazendo referência ao uso êmico, ou seja, feito pelas pessoas nos contextos pesquisados, ou remetendo ao emprego feito por alguma referência teórica utilizada. $\mathrm{Na}$ apropriação, optou-se pelo uso de 'gestantes que usam crack'.
Assim como o serviço que Barroso (2013) relaciona ao modelo de atenção psicossocial, o CR enfatiza o acolhimento do/da usuária/o a partir do atendimento ambulatorial.

Esse serviço foi estabelecido para atender às demandas de saúde da população em situação de rua, incluindo as pessoas em sofrimento decorrente de transtorno mental, consumo de crack, álcool e outras drogas, adotando a RD em suas abordagens (BRASIL, 2012). O trabalho no CR combina uma proposta de trabalho coletivo com a das consultas por profissional específico. Isso é evidenciado na comparação entre o atendimento "na rua' e 'na base'. Quando os/as profissionais estão na base, o espaço que existe são pequenas salas onde o acolhimento e atendimento ao/à usuário/a é realizado por um/a profissional por vez; ao passo que, na rua, o que se propõe como acolhimento humanizado (BRASIL, 2003A) é feito desde quando os profissionais descem da Kombi (meio de transporte utilizado): a equipe aproxima-se junta, escuta, conversa e oferece o atendimento. Nos trajetos entre um lugar e outro, na Kombi, a equipe reflete e debate sobre os casos conjuntamente.

Uma noção central nos atendimentos às gestantes que usam crack nesse serviço é o vínculo, o qual opera como elemento considerado fundamental para uma prática eficaz, para a adesão ao tratamento, mas também central para a noção de justiça acionada pelos/as profissionais. Nas descrições que seguem, busca-se evidenciar que o vínculo é entendido pelos/as profissionais como aspecto que possibilita a aproximação e o desenrolar do trabalho com as gestantes e permite avaliar os casos atendidos. Ainda, destaca-se que o modo de vínculo construído no CR é oportunizado pela estruturação da proposta desse serviço que requer uma aproximação dos/as profissionais às realidades e contextos de vida das pessoas.

Os/as profissionais referem que o primeiro contato é geralmente realizado na rua, quando encontram as mulheres grávidas, às vezes por acaso, outras por serem acionados por serviços ou pelas próprias pessoas que vivem na rua. Esse primeiro momento é denominado de 'captação':

É, sim, seria diferente porque na busca ativa a gente sabe o motivo, porque você está procurando o seu paciente. Na captação... às vezes, o que acontece, por exemplo, a gente vê a mulher, vê que está com sua barriga, então fala 'olha, mas você está grávida?', 'Ah, não sei, será?' 'Vamos fazer um teste'. Ou mesmo ela: 'Ah, eu acho que estou grávida, eu queria fazer um teste'. Tipo assim, ou a gente pergunta. Faz um teste, fizemos o primeiro contato e ali então a gente faz a captação. [...] Depois, a gente sempre trabalha com o vínculo, até porque muitas pacientes não são conhecidas, muitas pacientes não acessam o serviço, lembrando que aqui no consultório a maioria da porcentagem é de homens e não de mulheres. (Fabiane, Profissional de Saúde - CR).

Os primeiros contatos com as gestantes também apontam para o vínculo como uma estratégia que sustenta o trabalho no CR. Naquele espaço, percebe-se que o vínculo traduz proximidade, confiança e afeto, enquanto sua ausência, um certo distanciamento. Ele é acionado nos discursos das/ os profissionais ao falarem sobre o relacionamento com as usuárias ${ }^{2}$, mas salientam que é algo construído com o tempo. Ao contar sobre os atendimentos realizados com as gestantes que usam crack e outras drogas, Fabiane relatou a dificuldade que foi no início para a equipe criar um vínculo com uma das gestantes atendidas, Renata. Ela conta que passou semanas indo onde a usuária ficava, oferecendo o serviço, e, aos poucos, foram criando vínculo. Assim, menciona: "Que serviço que faz isso?”.

$\mathrm{O}$ estabelecimento do vínculo ocorre, sobretudo, com a equipe e concentra-se na figura de um/a ou outro/a profissional, que se torna referência para a usuária. $O$ caso de Renata ilustra a relação com a profissional de referência, que, nesse caso, foi uma 
das técnicas de enfermagem. Ao chegar no serviço, Renata já perguntava por essa técnica, a qual, mesmo não estando na função de acolhimento, sentava com a gestante em uma sala para conversarem desde questões relacionadas à gravidez, ao filho, ao seu tratamento, até as suas angústias e reclamações. Ainda, a técnica entregava os remédios e combinava com Renata o retorno ao CR e as consultas em outros serviços. Diversas vezes essa técnica lembrava à equipe ações relacionadas à Renata que precisavam ser realizadas, além de acompanhá-la nos atendimentos em outros serviços.

Devido às características do modelo de atenção com ênfase psicossocial - especialmente o atendimento no território e a diversificação de estratégias de cuidado que contemplem a participação de usuários/ as -, no CR é quase impossível que os/as profissionais não se conectem com as vidas das gestantes. Realizar um atendimento no contexto de vida dos sujeitos, conhecendo suas redes sociais, circulando e convivendo com usuários/as em outros espaços (como a rua, serviços de saúde ou assistência social, Centros POPs - Centro de Referência Especializado para População em Situação de Rua), possibilita aos/às profissionais uma percepção diferente daquelas pessoas do que seria se as vissem apenas no serviço (base). Desse modo, os/as profissionais percebem que existem muitas situações complicadas e produtoras de sofrimentos, e a droga não é a principal questão naquela(s) vida(s). Por conseguinte, essa aproximação ao contexto e o vínculo permitem outra relação entre profissionais e usuárias, o que reverbera em quais/como são propostas as estratégias de tratamento e como são consideradas as mulheres e a maternidade nesse contexto.

Nesse serviço, as concepções sobre drogas são entendidas em processo, pois os/as profissionais consideram que há determinados contextos e momentos que fazem a pessoa ficar mais propensa ao uso. Por isso, procuram, ainda, compreender o que se torna um problema para cada pessoa devido aos usos. A RD é adotada como proposta terapêutica não só por ser diretriz institucional, mas também porque é o modo como entendem ser possível realizar o cuidado com aquela população. A experiência do trabalho na rua, próximo ao contexto de vida das pessoas, escancara suas condições, e o vínculo construído entre profissionais e usuárias abre espaço para que conheçam suas histórias, desejos e preocupações, guinando nova direção à atenção à saúde. Um cuidado que visa à integralidade e, para isso, trabalha a partir da relação estabelecida entre profissional e usuária.

Contudo, quando se trata de uma gestante, a noção de RD entra em conflito, pois em comparação a demais usuários/as do serviço, pensar e desenvolver ações de cuidado a uma mulher que está grávida e faz uso de crack exige da equipe reflexão e superação de preconceitos. Esse conflito e constrangimento moral se conformam a partir das concepções que as/os profissionais do CR possuem sobre ser mãe e também devido à preocupação com a situação das crianças. Tais questões são discutidas e repensadas em grupo. Desse modo, no seguinte trecho de entrevista, um profissional aponta que a $\mathrm{RD}$ sustenta um modo de trabalhar com as gestantes usuárias de crack que produz resultados, porém implica um posicionamento ético-político sobre cuidado:

E eu era a única pessoa do Consultório na Rua que tinha um vínculo com ela e consegui fazer alguns avanços. Mas era sempre no tempo dela porque na maioria das vezes que eu chegava pra conversar ela estava noiada; ela conseguiu fazer duas doses de penicilina - de benzetacil - pro tratamento da sífilis; ela conseguiu fazer algumas consultas de pré-natal, mas eu fazia essas consultas sempre debaixo do viaduto. Mas conseguia levar ela pra fazer exames laboratoriais, ela fazia ecografia, mas tudo isso sempre respeitando também a vontade dela de usar crack. Não que isso seja algo simples pra ti enquanto cuidador. E daí a perspectiva de Redução de Danos 
te ajuda muito a pensar, e a tomar uma decisão sobre o caso. Pode ser que essa gestante - que foi a primeira que eu cuidei, que era usuária de crack - a gente tivesse feito uma internação compulsória pra ela, só que, como é Consultório na Rua, e trabalhar na rua estamos bastante expostos, também a versão dos usuários sobre o nosso trabalho, qualquer medida nesse sentido, ela percorre... toda a cidade. E daí a gente vai ser a equipe que interna gestantes contra a sua vontade, ainda mais uma pessoa ligada ao tráfico. E aí não se trata de medo - de modo nenhum. Se trata de saber que outras mulheres vão aparecer, que outras gestantes vão chegar até o nosso serviço e elas precisam confiar que a gente vai fazer de tudo, o possível para respeitar a suas liberdades individuais. Mesmo que isso nos cause angústia. (Pedro, Profissional de Saúde - CR).

Nesse espaço onde as histórias pessoais e os contextos de vida se mostram tão evidentes aos profissionais, a ideia de abstinência revela-se precária. Por mais que muitas vezes sejam contrários ao uso de drogas, especialmente, por gestantes, encontram novos modos de significar os motivos do uso e estratégias para trabalhar com as usuárias, compreendendo que é o melhor que pode ser feito. Ter uma orientação da proposta da RD não quer dizer que os/as profissionais não orientem sobre parar o uso de crack, álcool e outras drogas. Constroem projetos terapêuticos com as usuárias baseados em suas histórias, condições de vida, necessidades e desejos, mas consideram as particularidades em ser gestante, que impelem determinados procedimentos padrões, como a realização do pré-natal. De modo geral, as orientações e construção de estratégias de tratamento ocorrem por meio de conversas, na consulta na base ou ação na rua, em que discutem como a gestante se sente, o que a está incomodando, orientam sobre os riscos, sobre as patologias e, por fim, pensam modos de cuidado, como vai pegar o medicamento, como e quais serviços acessar.

$\mathrm{Na}$ medida em que os profissionais também são afetados por esse contexto, é como se o plano terapêutico os implicasse diretamente. Desse modo, quando algo não sai como o esperado, por exemplo, uma usuária 'não adere' às propostas, também é sentido mais profundamente pela equipe. $\mathrm{O}$ insucesso terapêutico é, muitas vezes, entendido como um insucesso dessa relação. A equipe parece desenvolver práticas diferenciadas de atenção ao seu público, o que poderia levar equipe e usuária a vincular-se mais, porém, poderia também criar expectativas. $\mathrm{O} / \mathrm{a}$ profissional, no lugar de cuidador/a, pode, assim, pensar que 'sabe o que é melhor', esperar que a gestante 'contribua', ou até retribua, fazendo 'o certo'. As ações das usuárias são lidas dentro desse vínculo que, além de formal, é percebido como afetivo, havendo possibilidade de relações de confiança que se traduzem em investimento no tratamento da gestante e em sua relação com o/a filho/a. Ainda, os/as profissionais percebem que a RD é uma estratégia que possibilita que a gestante se vincule ao serviço, aceite ser cuidada e realize o pré-natal. Enfim, o vínculo entre gestante e equipe, além de propiciar um cuidado mais próximo, também influencia no investimento que a equipe faz para que a mulher e seu companheiro tenham uma organização para permanecerem com o/a filho: arrumar um lugar para ficar ou pelo menos dormir (abrigo, albergue, aluguel social ou casa de algum parente) e prestar os cuidados básicos a essa criança (como saúde, alimentação, necessidades fisiológicas).

Desse modo, o CR além de responder a demandas construídas na lógica de saúde comunitária - evidenciando o sujeito e seu contexto social - também produz modos de ser profissional. Isto é, nesse espaço, as políticas públicas tensionam modos de ser profissional: por um lado propõe-se um cuidado para a autonomia, possuindo a RD como estratégia de tratamento; por outro, há diretrizes do Ministério da Saúde para um pré-natal ideal, exigência da rede de proteção à infância. 


\section{Unidade de Internação Psiquiátrica}

A Unidade de Internação Psiquiátrica (UIP) onde se realizou o trabalho de campo inscreve-se no modelo de atenção com ênfase hospitalar, já que é justamente voltada ao atendimento no âmbito hospitalar. A UIP faz parte de um hospital que é referência no estado para atenção à saúde de mulheres e de crianças. Nesse local, há cerca de 24 leitos psiquiátricos, sendo cinco para gestantes internadas com diagnóstico de dependência química, configurando o motivo da internação como 'risco ao concepto'. Ao passo que o uso de drogas é inscrito como doença pelos discursos circulantes no hospital, pretende-se circunstanciar essa concepção de uso de droga enquanto aspecto que orienta práticas profissionais.

A proposta de tratamento para gestantes é de internação de 28 dias para desintoxicação. Contudo, os profissionais relatam que algumas acabam ficando mais tempo por questões sociais, isto é, por não haver um local protegido para elas permanecerem até ganhar o bebê; tampouco a família fornece suporte para que elas se mantenham em casa. Em um dos rounds ${ }^{3}$, as profissionais ressaltam que a UIP é um local para internação de curta duração, compreendida como desintoxicação, inclusive porque é alto o custo de manter uma paciente na internação psiquiátrica. Referem que ali não é o lugar para uma paciente ficar porque não tem para onde ir, no entanto, ressaltam que "não há local adequado para dependente química" (DIÁRIO DE CAMPO H - 01/09/15).

Sendo assim, a permanência das gestantes na internação psiquiátrica até ganharem os filhos/as é justificada pelo intuito de proteção ao concepto. O que é entendido como fundamental, ainda mais por se tratar de um hospital amigo da criança:

[...] por ser o hospital Amigo da Criança, [...] nós já fomos chamados lá, a gente tem todo um compromisso selado, escrito, a secretaria de saúde tem de que as mães gestantes dependentes químicas, os bebês, as questões com relação ao bebê têm que ser obrigatoriamente encaminhadas para o Juizado da Infância e Juventude pra ser monitorados pelo juizado. (Anelise, Profissional de Saúde - H).

Contudo, o viés de proteção ao concepto também gera questionamentos sobre o tratamento oferecido às mulheres. A ponderação sobre a motivação como central no programa de tratamento é apontada por Bento:

\begin{abstract}
Aqui tu não tem como fazer isso, então a paciente pode estar super desmotivada, ser agressiva com a equipe, ser agressiva com ela mesma, mas tu tem que proteger o concepto, então tu meio que esquece a dependência química e fica preservando o concepto. Então, tu não tem como mandar embora uma gestante que tu sabe que vai usar, então ela fica aqui contra a vontade dela, sem aproveitar o tratamento, basicamente esperando o parto, e isso não é um tratamento, mais um modo de resguardar a saúde do bebê. (Bento, Profissional de Saúde - H).
\end{abstract}

Como o tratamento é voltado para a abstinência, a consecução dessa opera como um marcador para a avaliação de que a mulher pode ficar com seu/sua filho/a. Logo após esses bebês nascerem, há uma audiência em que o/a Juiz/a do Juizado da Infância e Juventude decide sobre a guarda dessa criança, informada por relatório da assistência social e laudos médicos. Um dos casos considerados sucesso que uma profissional relatou é o de uma mulher que foi para uma pensão protegida (lugar fechado) e depois de um ano continua lá com o bebê, e abstinente.

Os discursos correntes na UIP inscrevem o uso de drogas enquanto doença e, portanto, utilizam a denominação de dependência química. $\mathrm{O}$ entendimento enquanto uma doença "com bases neurofisiológicas" (Bento, Profissional de Saúde - H) adquirido pelo estudo ou trabalho na unidade é
3 Round é o momento em que a equipe se reúne para discutir os casos. 
contrastada com a concepção de que o uso de drogas é um vício que se desejou ter:

Entender as coisas como sintomas, e o contexto do paciente como pré-disposição, que ele tem um maior risco de usar, um maior risco de ter uma parte continuada de uso. (Bento, Profissional de Saúde - H).

Logo, a internação também é justificada como proteção a alguém que não consegue exercer esse cuidado sobre si, nesse caso sobre outro também.

Sob a perspectiva do uso de drogas como doença, um passo importante para se adequar às normas e ter uma vida regrada, civilizada - no julgamento dos/as profissionais de saúde -, é a desintoxicação (BARROso; KNAUTH; MACHADO, 2014). As autoras observam que, nessa concepção de cuidado, a não adesão ao tratamento é considerada desinteresse em cuidar de si e que resulta de um processo de passividade de um sujeito que se deixou dominar pela droga e isto terá consequências na sua relação com o serviço de saúde. A proposta de abstinência camufla as singularidades dos usos de crack, e das pessoas, na medida em que se baseia em uma homogeneização das experiências de uso. Aliada ao contexto de relacionamento entre profissionais e usuárias limitado ao hospital, a homogeneização dos usos ofusca a percepção dos/as profissionais ante as situações que particularizam as gestantes.

O discurso médico da 'dependência química’ instituiu a noção de uso de drogas como uma 'doença crônica', logo, incurável (ROMANINI; ROSO, 2013). Essa noção, respaldada em uma visão de mundo construída historicamente, identifica o uso de drogas como uma doença biológica/genética que requer tratamento e reabilitação (QUEIROZ, 2005). Nessas observações, percebeu-se que a compreensão do uso de crack como doença situa a gestante enquanto paciente que, por estar em desequilíbrio da saúde, necessita de cuidados para retornar a um estado 'normal'.
A concepção de dependência química atrela-se, também, à categorização das drogas, a qual se baseia em discursos jurídicos - o que é considerado legal e ilegal; na cultura - o que, onde, como, por quem é permitido usar; e conjuntamente no modelo com ênfase hospitalar, o qual justifica a escolha de determinadas substâncias devido a evidências científicas: medicamentos possuem uma regulação e estudos que detalham os riscos e benefícios, em contrapartida ao uso de crack, que é difícil saber exatamente quais consequências provoca para a pessoa e filho/a.

$\mathrm{Na}$ UIP, percebeu-se que a proteção aparece tanto da paciente em relação a sua doença quanto do bebê que ela espera. Assim, é o entendimento do uso de drogas enquanto doença que exige medidas de proteção, como é considerada a internação psiquiátrica. $\mathrm{O}$ tratamento proposto (desintoxicação) é no sentido de amenizar os sintomas da doença (fissura) e visar à abstinência, que seria próxima a uma ideia de cura. Não obstante, um dos profissionais parece retomar um questionamento sobre a cura:

Acho que a medicina tem uma coisa muito idealística de querer curar. E certas coisas não têm cura, às vezes tu tem que tentar aprimorar a qualidade de vida dentro do que aquela pessoa consegue. (Bento, Profissional de Saúde - H).

Apesar de não falarem em RD, a estratégia de tratamento acaba sendo questionada:

Aqui e no SUS em geral quase todas as internações de dependência química, elas não trabaIham com o que deveria ser trabalhado. Por falta de recursos, por falta de pessoal. A gente tem hoje pra dependência química de crack, especificamente, nenhuma medicação efetiva. Então, nenhuma medicação previne recaída e nenhuma medicação controla a fissura. O que o SUS faz muito aqui e no próprio [Nome de outro hospital] que é a referência, acaba dando antipsicótico e sedativos. Então dá clorpromazina, às vezes tenta dar um haldol, pro indivíduo ficar mais 
sedado, mas é uma coisa irrealística tu quer que a pessoa passe o resto da vida sedada pra não usar droga, né? Então, a pior abordagem e a que é mais usada, é a do tratamento farmacológico. Então, se tu tem uma paciente não motivada, tu tenta fazer uma abordagem mais motivacional. (Bento, Profissional de Saúde - H).

Durante a internação, os episódios de fissura são manejados verbalmente - profissionais conversam com pacientes, relembram técnicas, oferecem oficinas - ou com uso de medicamentos. Todavia, alguns/ algumas profissionais entendem que após a alta o contexto será diferente, e a paciente não terá o suporte que a equipe fornece no momento. Sendo assim, há o questionamento que a desintoxicação teria que ser conjugada a um tratamento motivacional.

A motivação, segundo os/as profissionais, é de extrema importância nesse processo. Segundo suas compreensões, a motivação opera no sentido de impulsionar e sustentar mudanças no comportamento - sobretudo, porque percebem que o contexto social, econômico, familiar, influenciou no início e continuação do uso. Por vezes, acaba sendo impossibilitada essa proposta já que é necessário, acima de tudo, manter a proteção ao concepto. Tal direcionamento da atenção está atrelado às questões institucionais e de políticas públicas, que promovem e exigem uma proteção às crianças de toda a rede de saúde, principalmente nesse hospital que tem o compromisso selado de ser 'amigo da criança'. Também se entende que essa proteção à criança é prioridade na equipe por questões pessoais e valores compartilhados socialmente e naquele grupo - do lugar de fragilidade, inocência e afetivo que a criança ocupa no imaginário social. Desse modo, entendem que o lugar da criança não deve ser na rua, com uma mãe que usa drogas, que provavelmente não prestará os cuidados necessários. Entre os aspectos que a equipe entende constituir uma boa mãe, a abstinência de drogas, a motivação e a adesão ao tratamento são alguns dos principais marcadores nesse contexto.

Enfim, parece ser um dilema para a equipe iniciar um tratamento que eles pressupõem que não será continuado após a alta, já que a adesão é baixa, e ressaltam que não há lugares adequados para encaminhar essas gestantes. Observou-se discursos que salientam que a internação de longa duração está em discussão, não podendo a UIP suprir a falha na rede de atenção a dependentes químicas. Desse modo, questionam o fato de a unidade ser um local para desintoxicação, uma internação que deveria durar cerca de 28 dias, e acaba mantendo pacientes por critérios sociais, ou seja, não terem o espaço protegido para seguir a gestação. A equipe entende que a UIP não é o local adequado para a gestante ficar além dos 28 dias, sendo, inclusive, mais oneroso ao Estado do que outros serviços; entretanto, mencionam a precariedade da rede para locais protetivos e, portanto, acabam mantendo algumas pacientes na UIP, que também não teriam o suporte familiar.

\section{Considerações finais}

Neste artigo, apresentaram-se resultados referentes à análise sobre a economia moral que permeia as práticas dos/as profissionais de saúde em relação à atenção a gestantes que usam crack, em uma de suas dimensões a dimensão atinente aos modelos de atenção enfatizados nos serviços analisados -, para apontar que os/as profissionais se inserem em lógicas mais amplas que conformam e influenciam suas escolhas, o que fazem, ou não, em suas práticas de saúde.

A etnografia, ao direcionar o olhar para as nuances e ambiguidades das práticas cotidianas, possibilitou perceber que as propostas terapêuticas estão intrinsecamente ligadas às concepções sobre drogas que circulam nos serviços de saúde. Tais concepções são produzidas e sustentadas pelas perspectivas 
ético-políticas acionadas em cada serviço, pela formação profissional e outras experiências de vida dos/as profissionais e ainda pela atualização de valores e normas sociais que cada equipe faz e que remete àquilo que pode ser enunciado naquele grupo.

O que parece movimentar a economia moral, em um serviço, é a ideia de vínculo com profissionais e filha/o, enquanto no outro, é a ideia de motivação em relação ao tratamento e cuidados com filho/a. As práticas que giraram em torno do vínculo ou da motivação não apenas produzem diferentes relações e afetos, mas também materializam diferentes modos de fazer justiça, constroem formas diferenciadas de acesso à cidadania e aos direitos. Apresentaram-se, neste artigo, alguns resultados referentes aos modelos de atenção e à conformação do cuidado, entretanto essa discussão levantou outras análises.

No CR, há uma ênfase no vínculo como aspecto que medeia as decisões terapêuticas e, por conseguinte, a avaliação sobre as gestantes - elaboração das propostas terapêuticas, o suporte para manterem a guarda dos seus bebês. Assim, o vínculo gerencia os afetos tornando-se chave para a noção de justiça, isto é, do que é certo de ser realizado. O estabelecimento do vínculo possibilita à/ ao profissional conhecer as histórias e contextos de vida das usuárias, e pode-se elaborar um projeto terapêutico que contemple suas singularidades. Por meio do vínculo, elas adquirem confiança com os/as profissionais, sendo assim, torna-se possível expressar sentimentos, canalizar frustrações, contar as situações que fogem à norma, as quais talvez fossem reprováveis por outros/ as profissionais - mas nesse contexto podem ser enunciadas, pois são suportadas.

Na UIP, a avaliação sobre a motivação da gestante para a cessação do uso de drogas informava estratégias de tratamento propostas, os encaminhamentos pós-alta, bem como providências em relação aos/às filhos/ as. A motivação de uma paciente pode ser percebida por meio de sua adesão ao tratamento, organização diária, demonstração de reconhecimento de episódios de fissura. Por conseguinte, a adesão à proposta terapêutica (desintoxicação, tratamento motivacional) é um dos principais aspectos que interatua nas condições de maternagem. Ainda, gestantes que na concepção dos/as profissionais aderiram ao tratamento, e constroem planejamentos para a continuidade desse tratamento e cuidados com os/as filhos/as, mobilizam a equipe de um modo que direcionam mais investimentos na relação profissionais-gestantes e gestante-bebê.

Entretanto, não só o modelo de atenção conforma práticas, mas a produção cotidiana pelos/as profissionais aos poucos influencia os modelos. Observando, notam-se ambiguidades nos discursos dos profissionais, que muitas vezes tomam a forma de questionamento sobre as propostas do modelo de atenção em que se inserem. Enfim, as práticas em saúde não dependem unicamente de características dos/as profissionais nem dizem respeito apenas a um modelo prescritivo, elas são justamente uma construção cotidiana que articula diversos elementos e sujeitos.

\section{Colaboradores}

Contribuição das autoras: Macedo e Machado contribuíram para a análise dos dados e para a elaboração do manuscrito e participaram da aprovação da versão final do manuscrito. 


\section{Referências}

BARROSO, P. F. Desintoxicar e Reinserir: perspectivas no tratamento dos usuários de drogas. 2013. $116 \mathrm{f}$. Dissertação (Mestrado em Antropologia Social) Universidade Federal do Rio Grande do Sul, Porto Alegre, 2013. Disponível em: <http://hdl.handle. net/10183/71941>. Acesso em: 28 out. 2015.

BARROSO, P. F.; KNAUTH, D. R.; MACHADO, P. S. Desintoxicação, medicamentos e reinserção social. In: FERREIRA, J.; FLEISCHER, S. (Org.). Etnografias em serviços de saúde. Rio de Janeiro: Garamond, 2014. p. 107-128.

BRASIL. Ministério da Saúde. Portaria ${ }^{\circ}$ 122, de 25 de janeiro de 2011. Define as diretrizes de organização e funcionamento das Equipes de Consultório na Rua. Diário Oficial [da] União. Brasília, DF, 26 jan. 2011. Disponível em: <http://bvsms.saude.gov.br/ bvs/saudelegis/gm/2012/prt0122_25_01_2012.html>. Acesso em: 16 dez. 2014.

Ministério da Saúde. Secretaria de Atenção à Saúde. Nota técnica conjunta/2012. Brasília, DF, 2012. Disponível em: <http://189.28.128.100/dab/docs/ geral/20120412004951716.pdf>. Acesso em: 23 nov. 2015.

Ministério da Saúde. Secretaria de Atenção à Saúde. Nota técnica conjunta $n^{\circ} 001$ - SAS E SEGEP. Brasília, DF, 2015. Disponível em: <http://portalsaude. saude.gov.br/images/pdf/2015/outubro/08/Nota-t-cnica--diretrizes-e-fluxograma-mulher-sit-rua.pdf >. Acesso em: 12 abr. 2016.

Ministério da Saúde. Secretaria Executiva. HumanizaSUS: política nacional de humanização. Brasília, DF: Ministério da Saúde, 2003a. Disponível em: <http://bvsms.saude.gov.br/bvs/publicacoes/ humanizaSus.pdf>. Acesso em: 21 dez. 2015.

Ministério da Saúde. Secretaria Executiva. $A$ Política do Ministério da Saúde para atenção integral a usuários de álcool e outras drogas. Brasília, DF: Ministério da Saúde, 2003b. Disponível em: <http:/livro aberto.ibict.br/handle/1/893>. Acesso em: 27 dez. 2015.
CONSELHO FEDERAL DE PSICOLOGIA (CFP). Referências Técnicas para a Atuação de Psicólogas/os em Políticas Públicas de Álcool e Outras Drogas. Brasília, DF: CFP, 2013. Disponível em: <http://www.crpll.org. br/consulta_l.pdf $>$. Acesso em: 2 out. 2014.

FASSIN, D. Compaixão e Repressão: A Economia Moral das Políticas de Imigração na França, Ponto Urbe, Tradução Gleicy Mailly da Silva e Pedro Lopes. São Paulo, v. 15, p. 1-22, 2014. Disponível em: <http:// pontourbe.revues.org/2467>. Acesso em: 12 abr. 2016.

Enforcing Order An Ethnography of Urban

Policing: Malden: Polity Press, 2013.

Public health as culture. The social construction of the childhood lead poisoning epidemic in France. British Medical Bulletin, Oxford, v. 69, n. 1, p. 167-177, 2004.

MACEDO, F. S.; ROSO, A.; LARA, M. P. Mulheres, saúde e uso de crack: a reprodução do novo racismo na/pela mídia televisiva. Saude soc., São Paulo, v. 24, n. 4, p. 1285-1298, 2015. Disponível em: <http://www. scielo.br/scielo.php?script=sci_arttext\&pid=S0104$12902015000401285 \& \operatorname{lng}=\mathrm{en} \& \mathrm{nrm}=\mathrm{iso}>$. Acesso em: 31 dez. 2015.

MERHY, E. E. O ato de cuidar: a alma dos serviços de saúde. In: BRASIL. Ministério da Saúde. Secretaria de Gestão do Trabalho e Educação na Saúde. Departamento de Gestão da Educação na Saúde. Ver-SUS Brasil: caderno de textos. Brasília, DF: Ministério da Saúde, p. 108-137, 2004. Disponível em: $<$ https://www.nescon.medicina.ufmg.br/biblioteca/ imagem/2103.pdf >. Acesso em: 19 dez. 2015.

O SUS e um dos seus dilemas: mudar a gestão e a lógica do processo de trabalho em saúde (um ensaio sobre a micropolítica do trabalho vivo). In: TEIXEIRA, S. F. (Org.). Democracia e Saúde. São Paulo: Cebes; Lemos, 1998. Disponível em: <http://www.uff.br/ saudecoletiva/professores/merhy/capitulos-01.pdf>. Acesso em: 19 dez. 2015. 
PAIM, J. Modelos de Atenção à Saúde no Brasil. In: GIOVANELLA, L. et al. (Org.). Políticas e Sistema de Saúde no Brasil. Rio de Janeiro: Editora FIOCRUZ, 2008, p. 547-573.

QUEIROZ, I. S. Norma de gênero e uso de drogas: normalização e diferença na experiência de mulheres. 2015. 249 f. Tese (Doutorado em Psicologia) - Universidade Federal de Minas Gerais, Belo Horizonte, 2015.

ROMANINI, M.; ROSO, A. Midiatização da cultura, criminalização e patologização dos usuários de crack: discursos e políticas. Temas em Psicologia, Ribeirão Preto, v. 21, p. 483-497, 2013.
ROSO, A. R. et al. Discourses about crack in the printed mass media. Estudos de Psicologia, Campinas, v. 30, n. 3 , p. 455-466, 2013.

TEIXEIRA, C. F.; SOLLA, J. P. Modelo de atenção à saúde: vigilância e saúde da família [Internet]. Salvador: Editora EDUFBA, 2006. Disponível em: < http://static. scielo.org/scielobooks/f7/pdf/teixeira-9788523209209. pdf $>$. Acesso em: 23 maio 2016

Recebido para publicação em janeiro de 2016

Versão final em maio de 2016

Conflito de interesses: inexistente

Suporte financeiro: não houve 